\title{
A detenção de solicitantes de refúgio nos estados unidos: da migração forçada à punição*
}

\section{The detention of asylum-seekers in the United States: from forced migration to punishment}

Thais Silva Menezes ${ }^{11}$

\footnotetext{
* Recebido em 01/11/2011
} Aprovado em 21/05/2012

Mestre pelo Programa de Pós-Graduação em Relações Internacionais do Instituto de Relações Internacionais (IRI) da Universidade de São Paulo (USP) - Email: thaissilvamenezes@ hotmail.com.

\section{Resumo}

A configuração atual do regime internacional dos refugiados é fruto da afirmação histórica de direitos humanos, estando, dessa forma, refúgio e direitos humanos intrinsecamente relacionados. A detenção de solicitantes de refúgio tem sido exemplo de como procedimentos internos dos países podem contrariar seus comprometimentos concernentes a direitos humanos e à proteção internacional; ela é prática comum durante o processo de determinação do status de refugiado, punindo o indivíduo forçado a deixar seu país de residência e buscar proteção em outro, inserindo-o no sistema penal ou em um sistema análogo ao prisional e, assim, violando de forma sistemática os direitos humanos de indivíduos que buscam somente a garantia dos seus direitos. Este trabalho analisa as características dessa prática visando demonstrar como ela, por violar direitos humanos, mina o instituto do refúgio - que tem como justificativa de existência o imperativo de respeito a esses direitos. Foca-se especificamente na detenção de solicitantes nos Estados Unidos, por ter sido ele um grande incentivador da criação dos regimes de direitos humanos e dos refugiados, por utilizar frequentemente em seu discurso o signo dos direitos humanos como parâmetro para atuação do Estado e por ser um dos países com maior número de refugiados reconhecidos.

Palavras-chave: Solicitantes de refúgio. Detenção. Violação de direitos humanos. Estados Unidos.

\section{Abstract}

The present situation of the refugee international regime is a result of the historical affirmation of human rights, so that refuge and human rights are intrinsically related. The detention of asylum-seekers is an example of how internal procedures of the countries can oppose their commitments to human rights and to international protection: it is an usual practice during the process of refugee status determination, punishing the person forced to leave her/his country and seek international protection, introducing her/him into the penal system or into a prison-like system and, thus, systematically violating the rights of people who only seek the guaranty of their rights. This paper analyzes the characteristics of this practice and aims to demonstrate how it undermines the refuge - which exists exactly because of the imperative of respect for these rights - due to the human rights violations it encompasses. We concentrate specifically on the detention of asylum-seekers in the United States, because it was a great booster for the creation of the 
human rights and refugee international regimes, because it frequently uses the discourse of the human rights as parameter for the action of the states and for being one of the countries which have the largest numbers of refugees.

Keywords: Asylum-seekers. Detention. Human rights violation. United States.

\section{Introdução}

A migração forçada ocorre em um contexto no qual não existe a opção de permanência do indivíduo em seu local de moradia, seja devido a mudanças no meio físico - como no caso de grave degradação do meio ambiente, acidentes nucleares e projetos de desenvolvimento -, a situações de violência generalizada - conflitos - ou a violações de direitos humanos. São diversas as formas de concretização desse tipo de movimento migratório - o que claramente decorre dos inúmeros motivos específicos que podem obrigar um indivíduo a se deslocar do seu local de residência -, podendo, assim, originar deslocados internos, apátridas, migrantes climáticos e refugiados.

Os refugiados são englobados por um dos regimes mais institucionalizados do cenário internacional, o qual é composto por tratados internacionais (Convenção de 1951, Protocolo de 1967 etc.), agências internacionais (Alto Comissariado das Nações Unidas para os Refugiados - ACNUR -, Agência das Nações Unidas de Assistência aos Refugiados Palestinos no Oriente Próximo - sigla em inglês UNRWA) e organizações da sociedade civil (Cáritas Internacional etc.). Formulado em meio a uma afirmação histórica de direitos humanos e como resultado desse reconhecimento de direitos, a concepção contemporânea do refúgio visa "[...] à proteção da pessoa humana, em face da sua falta no território de origem ou residência do solicitante, a fim de assegurar e garantir os requisitos mínimos de vida e dignidade [...]" (JUBILUT, 2007, p. 43).

Embora falar em refúgio implique necessariamente em invocar parâmetros de direitos humanos - de proteção à vida e à dignidade da pessoa humana -, o instituto do refúgio também pode ser permeado por, ou, mesmo baseado, em provisões que contrariam a ideia amplamente difundida de direitos humanos. Uma situação na qual é clara tal violação de direitos é aquela em que solicitantes de re- fúgio ${ }^{2}$ são privados de sua liberdade até que seu processo de determinação de status de refugiado seja concluído. Tal prática, redundantemente condenada por organismos que tratam da questão dos refugiados, é bastante utilizada pelos Estados, contrariando importantes considerações de direitos humanos e a própria ideia de refúgio.

Este artigo aborda, dessa forma, a questão da privação de liberdade dos solicitantes de asilo no decorrer do processo de determinação do status de refugiado, a fim de demonstrar como essa prática contraria preceitos de direitos humanos e, portanto, solapa o instituto do refúgio, o qual deve objetivar a proteção do indivíduo. O enfoque da análise serão os Estados Unidos, grande propagador do discurso dos direitos humanos como parâmetro de ação, o qual foi um dos grandes incentivadores dos regimes internacionais dos direitos humanos e dos refugiados e um dos países que mais abrigam refugiados reconhecidos, mas que, contrariamente a toda história e discurso, vem sendo um dos principais Estados a deter aqueles que chegam ao seu território buscando proteção internacional.

\section{Da migração forçada}

O refúgio, como um instituto jurídico global, nasceu no seio da Liga das Nações (ANDRADE, 1996), quando, em 1921, foi criado o Alto Comissariado para os Refugiados Russos. Com a sucessão de diversos organismos e documentos formulados para tratar do tema dos refugiados na esfera internacional, ${ }^{3}$ o que se construiu foi um regime internacional dos refugiados contemporâneo, o qual se fundamenta em uma concepção do refúgio intrinsecamente vinculada à afirmação histórica de direitos

2 Embora na América Latina - sobretudo - haja uma diferenciação entre asilo e refúgio, na maior parte do mundo esses termos são utilizados intercambiavelmente. Considerando que nos Estados Unidos (foco do presente artigo), asylum e refuge possuem o mesmo significado, estes serão utilizados como sinônimos neste trabalho. Sobre especificações concernentes às diferenças entre asilo e refúgio vide: Jubilut (2007) e Barreto ( 2006).

3 Alto Comissariado para Refugiados (judeus e outros) provenientes da Alemanha, 1933; Convenção Relativa ao Estatuto Internacional dos Refugiados, 1933; Alto Comissariado da Liga das Nações para os Refugiados, 1938; Comitê Intergovernamental para os Refugiados, 1938; Convenção Relativa ao Estatuto dos Refugiados Provenientes da Alemanha, 1938; Organização Internacional para os Refugiados, 1948. 
humanos. Tal concepção tem como marco definidor a Convenção de 1951, relativa ao Estatuto dos Refugiado$s^{4}$ e formulada após a criação, em 1950, do Alto Comissariado das Nações Unidas para os Refugiados (ACNUR) - ainda hoje, o organismo internacional mais importante para o trato da questão. Segundo esse documento - e seu Protocolo Relativo de 1967, o qual modificou algumas de suas disposições, ampliando seu escopo - é considerada refugiada qualquer pessoa que:

[...] temendo ser perseguida por motivos de raça, religião, nacionalidade, grupo social ou opiniões políticas, se encontra fora do país de sua nacionalidade e que não pode ou, em virtude desse temor não quer valer-se da proteção desse país, ou que, se não tem nacionalidade e se encontra fora do país no qual tinha sua residência habitual, não pode ou, devido ao referido temor, não quer voltar a ele (ONU, 1951).

Criou-se, então, um regime internacional em que os países convergem no que se refere ao entendimento do que seria um refugiado, além de reconhecerem diversos direitos a serem assegurados a esses indivíduos, devido ao caráter forçado - decorrente de um dos cinco motivos mencionados - de sua saída do país de origem ou residência. A Convenção estabelece parâmetros comuns a serem utilizados em relação aos refugiados, mas é de responsabilidade de cada Estado (mesmo que, em teoria, conforme as disposições acordadas) determinar os mecanismos por meio dos quais o status de refugiado será reconhecido.

É amplamente admitida pelos estudiosos da questão dos direitos humanos, assim como pelos que analisam o refúgio, a intrínseca relação entre essas duas esferas, ${ }^{5}$ sendo que, de fato, o instituto do refúgio é decorrente do chamado de "direito de asilo", explicitado em vários documentos internacionais. ${ }^{6}$

O "direito de asilo" e, consequentemente, o instituto do refúgio são expressão do reconhecimento no âmbito internacional de direitos básicos inalienáveis, os quais, não sendo assegurados pelo Estado de origem ou residência de um indivíduo, devem lhe ser garantidos por outro país, no qual ele requeira tal proteção. Isso porque,

4 Doravante, denominada "Convenção" ou "Convenção de 1951".

5 Como: Crisp (2000); Feller (2000-2001); Foster (2007); Gorlick (2003); e Mcnamara (1999).

6 Declaração Universal dos Direitos Humanos (art. 14 (1)); Convenção Americana de Direitos Humanos (art. 22 \$7) e Carta Africana dos Direitos Humanos e dos Povos (art. 12 (3)). como afirmado na Declaração Universal dos Direitos Humanos (DUDH), “Todo ser humano tem capacidade para gozar os direitos e as liberdades [...]" (ONU, 1948), reconhecidos em diversos instrumentos como essenciais para preservação da dignidade humana, sendo que, para tal - como enunciado no preâmbulo da Declaração -, os Estados se comprometeram a, por meio de cooperação internacional, assegurar um mundo em que todos gozem de liberdade de palavra, de crença e da liberdade para viverem longe do temor e da necessidade (ONU, 1948). Essa é, sem dúvida, a razão maior para a adoção de um instrumento internacional de proteção - a Convenção de 1951 - que, por meio de uma concertação internacional, visa que a proteção à pessoa e a garantia de seus direitos se deem não obstante (e devido à) sua saída forçada de seu território de origem.

É importante ressaltar ainda que, conquanto sua condição de refugiado, o indivíduo não perde sua condição de ser humano, de modo que não se legitima a desconsideração dos direitos que lhe foram internacionalmente reconhecidos. Desse modo, não somente devido à vinculação entre direitos humanos e refúgio, mas também e, principalmente, à sua condição como sujeito de direitos, é que os direitos humanos dos refugiados devem ser respeitados antes, durante e depois do processo de solicitação de asilo (CANÇADO, 1999).

Segundo Ibhawoh (2003), nas últimas décadas se tem visto um progressivo entrelaço das linhas entre os estudos dos refugiados e do discurso dos direitos humanos. Nesse contexto, a admissão de solicitantes de asilo, seu tratamento e reconhecimento do status de refugiado se tornaram elementos cruciais do sistema internacional para a proteção dos direitos humanos, assim como a proteção é o que leva à admissão de solicitantes e à concessão do refúgio.

Loescher (2009) também sustenta que o regime internacional referente aos refugiados surge em meio ao reconhecimento da importância dos direitos humanos e que a expansão de um regime de refugiados, o qual se funda na ideia de que eles devem ter proteção internacional, é notável e tem sido um exemplo fundamental da importância crescente dos direitos humanos nas questões internacionais nos últimos sessenta anos.

Observa-se pela definição de "refugiado" que a perseguição desponta como elemento crucial para verifi- 
cação dessa condição. Esse elemento pode ser entendido de duas formas: a primeira, mais ampla, implica que a violação de direitos humanos, de forma sistemática e duradoura, representa a perseguição que legitima o reconhecimento do status de refugiado; a segunda, mais restrita, entende como parâmetro para o reconhecimento dessa condição somente a ameaça imediata à vida, à liberdade ou à segurança.

No primeiro caso, fica evidente a relação entre a violação de direitos humanos e a existência do refúgio enquanto instituto de proteção internacional; do segundo, embora mais restritivo, também é possível inferir tal vinculação, uma vez que vida, liberdade e segurança são os direitos humanos mais essenciais reconhecidos no âmbito internacional e aos quais todos os outros se vinculam. Nesse sentido, é sempre uma violação de direitos humanos (ainda que de alguns em específico) que leva à invocação do direito ao refúgio.

O progressivo entendimento da relação direta entre direitos humanos e refúgio, seja para o reconhecimento do status, seja para a concretização da proteção ao refugiado, já se tornou um ponto pacífico entre os estudiosos da questão. No entanto, há formas cruéis de se desconsiderar toda essa vinculação entre direitos humanos e refugiados. A privação da liberdade é uma delas.

\section{A punição: privação de liberdade}

\subsection{Nos estados unidos, a prática}

A questão da detenção de solicitantes de asilo não é um tema novo nos debates sobre o refúgio. Já em 1986, a temática despontava como preocupação dos organismos que lidam com refugiados, de modo que o ACNUR publicou uma nota em que clamou que as medidas de detenção - entendida então como o confinamento em determinada área, abarcando, portanto, os campos fechados - somente fossem utilizadas em casos estritamente necessários e por curto período (UNHCR, 1986). Não obstante todas as discussões, que ao longo do tempo vêm ressaltando os efeitos negativos dessa prática e a discordância dela com preceitos acordados internacionalmente, um grande número de países tem, ainda, submetido os solicitantes à detenção ou a medidas restritivas similares - como Austrália, Tailândia, Reino Unido, França, Alemanha, Itália, Canadá e Estados Unidos (WELCH; SCHUSTER, 2005;
FIELD; EDWARDS, 2006). Assim, embora venha sendo discutido há algum tempo, o tema apresenta grande relevância no contexto atual do refúgio e dos direitos humanos.

Em muitos Estados, a decisão de deter baseia-se em poderes discricionários, não prescritos pela lei. Frequentemente, mesmo quando estabelecida por lei, é aplicada de maneira arbitrária. Tais detenções são justificadas sob o rótulo de "segurança nacional", em um discurso que afirma o receio de que os solicitantes se evadam antes da finalização do processo de determinação do status de refugiado ou que não se apresentem para remoção, caso seja declarada sua inelegibilidade para o refúgio (UNHCR, 1999). Muitas jurisdições tornam obrigatória a detenção quando as pessoas não têm documentos de identidade ou apresentam documentos falsos, ignorando o fato de que esses indivíduos estão fugindo de seus países (UNHCR, 1999), estando, portanto, inseridos em um contexto no qual sua não identificação é elemento crucial para o sucesso de sua fuga.

Esses indivíduos são, assim, detidos por longo e indefinido período de tempo, devido à sua presença ou entrada ilegal nos países em que buscam proteção (AMNESTY INTERNATIONAL, 2007). A detenção tornou-se, dessa forma, um problema recorrente de proteção para o ACNUR, o qual constantemente tem demonstrado preocupação e contrariedade à prática. Em 1995, o Escritório lançou o documento "Diretrizes sobre a Detenção de Solicitantes de Asilo", no qual reafirmou que a detenção de solicitantes de asilo deve ser uma exceção e não a regra, e ressaltou a existência de diversas alternativas à detenção, como exigência de relatórios e de residência, liberdade sob fiança e estadia em centros abertos onde a presença pode ser monitorada (UNHCR, 1999).

Contrariamente às recomendações do ACNUR, diversos países continuam a deter solicitantes. Nos Estados Unidos, esses indivíduos são, muitas vezes, mantidos em prisões comuns, junto com prisioneiros preventivos ou com pessoas já sentenciadas por crimes de todos os gêneros. Mesmo quando encaminhados a "centros de detenção imigratória", convivem com o fato de que tais instalações funcionam como verdadeiras prisões, nas quais os detidos são obrigados a usar uniformes, são vigiados por funcionários com vestes de prisão, o "contato" com familiares e amigos é feito somente através de vidro e não existe basicamente nenhuma liberdade de movimento ou 
privacidade (HUMAN RIGHTS FIRST, 2009). Ademais, são frequentemente algemados em seus trajetos fora do espaço das instalações de detenção. Algumas outras detenções, ainda, superlotadas, falham em separar homens e mulheres, não têm estrutura apropriada - como sanitários e chuveiros individuais - e os espaços externos para uso recreativo são extremamente limitados (USCIRF, 2005a). Outros problemas referem-se a abusos cometidos pelos guardas, acesso inadequado a recursos legais, má qualidade do ar e de iluminação, poluição sonora, qualidade e quantidade de alimentos, proibição de recebimento de encomendas externas e furto de objetos pessoais (ALEXANDER, 2000).

O que se tem, portanto, é um contexto no qual indivíduos obrigados a deixar seu país de residência, ao clamarem por proteção internacional, são inseridos em um sistema prisional ou análogo ao prisional, tendo sua liberdade privada - o que contraria amplamente a ideia em que se baseia o regime internacional de direitos humanos e o de refugiados, punindo aqueles cujo "crime" foi procurar refúgio em outro país, já que sua vida, liberdade ou segurança estavam sendo ameaçadas em seu local de moradia habitual. Frente ao discurso da segurança nacional, os organismos que lidam com a questão têm clamado que, ao menos a detenção ocorra somente quando estritamente necessário e que seja proporcional ao objetivo a ser atingido; que seja baseada em lei prescrita; que exista possibilidade de revisão e que dure o menor tempo possível (HUMAN RIGHTS FIRST, 2009). A realidade, no entanto, contradiz fortemente essas recomendações, de modo que o regime internacional dos refugiados enfrenta grandes contradições decorrentes da prática da detenção dos solicitantes de refúgio.

\subsection{Nos Estados Unidos, o desrespeito}

A responsabilidade sobre as questões de imigração e refúgio nos Estados Unidos é do Departamento de Segurança Interna (DHS) - Department of Homeland Security -, no qual está alocado o Serviço de Imigração e Alfândega (ICE) - Immigration and Customs Enforcement -, agência responsável pela detenção imigratória. A detenção de não cidadãos, inclusive dos solicitantes de refúgio, é determinada pelo Ato de Imigração e Nacionalidade (INA) - Immigration and Nationality Act -, cuja configuração em relação aos solicitantes de refúgio é decorrente de uma reforma de 1996, estabelecida pelo Ato de Reforma sobre Imigração Ilegal e Responsabilidade Imigrante - Illegal immigration Reform and Immigrant Responsability Act (NAUMIK, 2008).

Quando um estrangeiro chega aos Estados Unidos e é declarado inadmissível, devido à falta de documentos apropriados, ele entra automaticamente em processo de "remoção expressa" (expedited removal), sem possibilidade alguma de audiência ou revisão dessa determinação, a menos que ele declare medo de perseguição ou intenção de solicitar asilo. Caso faça tais declarações, essa pessoa é detida e encaminhada a uma entrevista com um "oficial de asilo", para que seja verificado se há realmente um "temor crível” (credible fear) de perseguição (INA, Sec. 235). Tal temor é definido como a existência de possibilidade significativa de que, levando em consideração a credibilidade das afirmações feitas pelo estrangeiro em sustentação à sua reivindicação e outros fatos conhecidos pelo oficial, o estrangeiro possa estabelecer elegibilidade para o asilo nos Estados Unidos ${ }^{7}$ (INA, Sec. 235(b)(1)(B)(v)). Se $o$ oficial determinar que o estrangeiro não apresenta esse "crível temor", deve ordenar que seja removido dos Estados Unidos. Um Procurador-Geral pode estipular, após pedido do estrangeiro, uma revisão da determinação do "temor crível" por um juiz de imigração (INA, Sec. 235(b) (1)(B)(iii)(III)). Caso o oficial ou o juiz de imigração determine que há um "temor crível", o estrangeiro deve ser detido para considerações subsequentes sobre sua candidatura ao asilo (INA, Sec. 235(b)(1)(B)(ii)). É interessante notar que não se estabelece prazo para condução da entrevista de "temor crível" e a revisão por um juiz "não deve demorar mais de sete dias" (INA, Sec. 235(b)(1)(B) (iii)(III)), o que não garante que ela ocorra dentro desse período ${ }^{8}$ - enquanto ela não acontece, o estrangeiro é mantido detido.

Os Estados Unidos traçam uma diferenciação entre solicitantes "afirmativos" e "defensivos", sendo os primeiros aqueles que apresentaram seu pedido de refúgio sem terem sido apreendidos devido à sua presença ilegal, e os últimos, aqueles cuja reivindicação por asilo é vis-

\footnotetext{
7 A elegibilidade para o asilo é estabelecida na seção 208 do INA.

8 Há relatos de solicitantes de asilo que não tiveram sua entrevista de "temor crível" por várias semanas ou meses, o que atrasa sua possibilidade de se candidatarem à liberdade condicional (HUMAN RIGHTS FIRST, 2009).
} 
ta como reativa, ou seja, somente alegaram necessidade de proteção após serem barrados em pontos de entrada no país ou presos (os que já haviam sido admitidos no território estadunidense) (FIELD; EDWARDS, 2006). O procedimento de "remoção expressa" é aplicado aos "defensivos", de forma que os "afirmativos" raramente são detidos. ${ }^{9}$

Existe um procedimento de liberdade condicional (parole), estabelecido pelo Title 8 of Code of Federal Regulations, que somente é possível após a determinação do "temor crível" e, para sua obtenção, os solicitantes de asilo enfrentam diversas dificuldades, principalmente porque o processo para sua obtenção coincide com as disposições aplicadas aos imigrantes em geral. A liberação é avaliada caso a caso, após pedido do solicitante, ${ }^{10}$ e somente é concedida caso haja "razões humanitárias urgentes" ou "benefício público significativo" e desde que o indivíduo não represente um risco à segurança ou apresente possibilidade de fuga. Entre os grupos que podem ser "beneficiados" pela liberdade condicional estão: aqueles que apresentam sérias condições médicas; gestantes; menores de 18 anos; testemunhas em processos conduzidos nos Estados Unidos e aqueles cuja detenção não é de interesse público ${ }^{11}$ (8 CRF, Sec. 212.5 (b)).

O processo de liberdade condicional é extremamente falho. A decisão de liberar o solicitante de asilo é atribuída ao ICE, a mesma autoridade que o detém, não sendo possível uma apelação a um juiz sobre a decisão de manutenção da detenção. Frequentemente, a decisão de liberar o indivíduo relaciona-se a fatores que não aqueles elencados na legislação estadunidense (mencionados acima), como a disponibilidade de cama para sua acomodação (HUMAN RIGHTS FIRST, 2009; ALEXANDER, 2000), a porta de entrada no país, o gênero, a nacionalidade ou a religião do solicitante (USCIRF, 2005b). Na prática, diversos solicitantes que preenchem os requisitos para a liberdade, contudo, frequentemente permanecem nos centros de detenção. Os responsáveis frequentemen-

\footnotetext{
9 Segundo relatório do ICE ao Congresso em 2007 - último ano em que esses dados foram apresentados: 254 dos 24.908 solicitantes "afirmativos" estavam detidos; 4.614 dos 5.219 já com "temor crível verificado" continuavam detidos e 5.103 de 6.799 dos solicitantes "defensivos" estavam em detenções (ICE, 2008).

${ }^{10}$ Veremos na seção 2.4 deste artigo que essa disposição foi recentemente modificada.

${ }^{11}$ A expressão "interesse público" não é definida.
}

te ignoram ou aplicam seletivamente os critérios para a liberdade condicional, o que somente confirma que eles existem mais como um direcionamento que como regulamentações formais (WELCH; SCHUSTER, 2005), transformando tal procedimento em arbitrário (ALEXANDER, 2000). ${ }^{12}$

As políticas de liberdade condicional têm se tornado cada vez mais restritivas, com números assustadores: entre 2004 e 2007, as taxas de liberdade condicional concedida aos solicitantes caíram de 41,3 para $4,2 \%$ (HUMAN RIGHTS FIRST, 2009). Mais de 48 mil solicitantes de asilo foram detidos em prisões ou centros de detenção entre 2003 e $2009 .{ }^{13}$ Conforme estatísticas de 2007 do governo dos Estados Unidos, a maioria dos solicitantes de asilo é detida em média por três meses (ICE, 2008), todavia, segundo pesquisa da Human Rights First, a média seria de 5 a 6 meses (HUMAN RIGHTS FIRST, 2009).

O que se constata, portanto, é que, nos Estados Unidos, solicitantes de asilo são detidos devido a violações administrativas de imigração, sendo que o ICE mantém esses indivíduos em prisões comuns ou em centros análogos aos prisionais administrados por ele mesmo ou por empresas privadas. O DHS, entre 2004 e 2009, aumentou seu uso de instalações análogas às prisionais em pelo menos $62 \%$, com a construção de seis novas mega-instalações (HUMAN RIGHTS FIRST, 2009). Isso contraria recomendações do ACNUR e de outros organismos - que invocam a diminuição da recorrência a esse tipo de procedimento - e ignora os benefícios decorrentes da diminuição da prática, como a economia de grande quantidade de recursos. ${ }^{14}$ Desconsidera, principalmente, as necessidades decorrentes da condição de indivíduos fugindo de violação de direitos humanos: um grupo altamente vulnerável, frequentemente com uma carga de

\footnotetext{
${ }^{12}$ Desde os eventos de 11 de setembro de 2001, outras medidas têm imposto ainda maiores restrições aos solicitantes, como as derivadas da "Operation Liberty Shield" - que determinou a detenção de solicitantes de refúgio de indivíduos originários de 33 países de atuação conhecida da Al Qaeda (WELCH; SCHUSTER, 2005).

${ }^{13}$ O ICE não fornece informação estatística completa sobre esses anos, por isso o número não é exato, somente se sabe que excede 48 mil (HUMAN RIGHTS FIRST, 2009).

${ }^{14}$ Entre 2003 e 2009, o custo de detenção de solicitantes de refúgio nos Estados Unidos excedeu os 300 milhões de dólares. Enquanto o custo de detenção é de, em média, 95 dólares por dia para cada indivíduo, as medidas alternativas custam de 10 a 14 dólares (EDWARDS, 2011).
} 
aprisionamento e tortura em seu país de origem, necessitando de apoio da família e de amigos.

A privação de liberdade dos solicitantes de asilo gera uma infinidade de prejuízos para o indivíduo, entre os quais se destacam:

1) Geralmente os centros de detenção estão localizados em áreas remotas, o que leva a dois efeitos:

a) os solicitantes têm uma menor possibilidade de acesso à representação legal, já que o sistema civil de imigração não provê representantes para indivíduos que não podem arcar com essas despesas. Geralmente, a representação dos solicitantes se dá mediante ação voluntária de advogados e organizações civis. A falta de acesso à representação implica grave prejuízo, já que estatísticas demonstram que quando representados, sua probabilidade de liberação aumenta consideravelmente, assim como sua probabilidade de reconhecimento como refugiado (HUMAN RIGHTS FIRST, 2009);

b) mantidos em detenção, as entrevistas para consideração do reconhecimento do status de refugiado são frequentemente conduzidas por vídeo. Um estudo recente demonstra que entrevistas por vídeo diminuem em $50 \%$ a probabilidade desse reconhecimento ${ }^{15}$ (HUMAN RIGHTS FIRST, 2009).

2) A detenção impacta a capacidade do solicitante de preparar seus casos, juntar evidências, contatar testemunhas potenciais, conduzir pesquisas e, assim, determinar sua elegibilidade para o asilo (HUMAN RIGHTS FIRST, 2009) - já que o ônus da prova da condição de refugiado é do solicitante (INA, Sec. 208 (a)(3)(b)(1)(B)).

3) Há sérias deficiências na provisão de cuidados médicos aos solicitantes detidos, como falta de médicos, falhas de comunicação, demora e acúmulo de pedidos de atenção médica (HUMAN RIGHTS FIRST, 2009; ALEXANDER, 2000).

4) Efeitos psicológicos: a detenção tem graves efeitos sobre uma população já traumatizada, sendo verificados altos níveis de ansiedade, depressão e stress pós-traumático (PHR; BELLEVUE/NYU, 2003). Alguns

\footnotetext{
${ }^{15}$ A videoconferência altera a percepção do juiz sobre o testemunho do solicitante devido ao fato de que essa tecnologia não capta e transmite acuradamente elementos não verbais, algumas mudanças de tom e linguagem corporal (HUMAN RIGHTS FIRST, 2009).
}

solicitantes, inclusive, abandonam seus requerimentos de asilo por não suportarem mais a detenção (HUMAN RIGHTS FIRST, 2009). Outros apodem ter restringida sua capacidade de defender a reivindicação de asilo devido à comprometida saúde mental (ALEXANDER, 2000). Ademais, quando reconhecido o status de refugiado, os danos decorrentes da detenção podem interferir na integração na sociedade estadunidense.

Os padrões de detenção descritos assemelham-se fortemente e, de fato, são baseados em padrões de instituições corretivas, o que, segundo a Comissão sobre Liberdade Religiosa Internacional dos Estados Unidos (sigla em inglês USCIRF), contribui para a ideia de que os solicitantes estão sendo criminalizados - devido às condições em que são confinados (USCIRF, 2005b). Acreditamos, no entanto, que tal fato não somente contribui para essa ideia, como na verdade é baseado em uma visão criminalizada e criminalizante dos solicitantes de refúgio. A privação de liberdade dos solicitantes de asilo é a representação material do completo desrespeito a padrões acordados internacionalmente por meio do englobamento das questões relacionadas ao refúgio (de modo absurdo) pela (já absurda) ideia de “[...] criminalização das migrações internacionais, ou da visão do estrangeiro, do diferente, como um potencial criminoso ou terrorista" (OLIVEIRA, 2007, p. 326).

\subsection{Considerando as disposições internacionais: a violação}

A detenção de solicitantes de asilo contraria sistematicamente diversas provisões de documentos internacionais que se referem aos refugiados especificamente, assim como a direitos humanos, de maneira mais ampla documentos dos quais os Estados Unidos são signatários, além de terem desempenhado papel crucial para sua elaboração. Já na DUDH, de 1948, a liberdade foi reconhecida como direito inalienável ao se afirmar que: "Ninguém pode ser arbitrariamente preso, detido ou exilado" (art. $9^{\circ}$ ). Esta Declaração explicitou as bases sobre as quais os tratados sobre direitos humanos subsequentes seriam formulados, como a Convenção Relativa ao Estatuto dos Refugiados, 1951, e o Pacto Internacional dos Direitos Civis e Políticos (PIDCP), 1966.

Os Estados Unidos ratificaram o PIDCP em 1992, estabelecendo dessa forma seu compromisso - ao menos 
formal - com as disposições por ele estabelecidas. Entre os diversos reconhecimentos de direitos nele explicitados, está o direito à liberdade e a proibição da prisão ou detenção arbitrária. Dessa forma, afirma que:

Art. $9^{\circ} \$ 1$ Toda pessoa tem direito à liberdade e à segurança pessoais. Ninguém poderá ser preso ou encarcerado arbitrariamente. Ninguém poderá ser privado de sua liberdade, salvo motivos previstos em lei e em conformidade com os procedimentos nela estabelecidos (ONU, 1966).

Ainda estabelece que:

Art. $9^{\circ}, \$ 4$ Qualquer pessoa que seja privada de sua liberdade, por prisão ou encarceramento, terá o direito de recorrer a um tribunal para que este decida sobre a legalidade de seu encarceramento e ordene a soltura, caso a prisão tenha sido ilegal (ONU, 1966).

E, por fim, sustenta que "As pessoas processadas deverão ser separadas, salvo em circunstâncias excepcionais, das pessoas condenadas e receber tratamento distinto, condizente com sua condição de pessoas não condenadas" (Art. $10 \$ 1$ (a) (ONU, 1966).

Todas as disposições do PIDCP acima mencionadas são ignoradas pela prática da detenção dos solicitantes de refúgio nos Estados Unidos. O imperativo de que a detenção não seja arbitrária significa que ela deve ser submetida a restrições, incluindo a concordância com a lei, a justificação no caso individual como medida necessária e proporcional, a conformidade com o direito internacional, a sujeição à revisão judicial e uma duração de curto período (AMNESTY INTERNATIONAL, 2007). Embora a detenção de solicitantes seja estabelecida por lei - no INA -, não é um órgão judicial que a determina e a acompanha em cada caso específico, de modo que ela passa a ser uma decisão administrativa e não judicial. O seu caráter administrativo está ainda evidente no fato de que é o ICE que considera os pedidos de liberdade condicional, não sendo possível a revisão de tal decisão, sequer por um juiz de imigração; sendo o ICE, assim, o único responsável pela detenção, assim como pela liberação condicional do solicitante. Desse modo, a detenção é obrigatória a qualquer solicitante colocado em processo de "remoção expressa", não há avaliação caso a caso da necessidade de se deter aquele indivíduo e o solicitante somente tem a possibilidade de ser "beneficiado" pela liberdade condicional.

Ademais, conforme descrito anteriormente, a exigência de separação de pessoas processadas das condenadas, assim como de distinção de tratamento são também frequentemente ignoradas. Os solicitantes sequer estão sendo realmente processados; de fato, seu pedido de reconhecimento como refugiado, um indivíduo que busca e tem direito à proteção internacional, é o que está sob análise, de modo que, se já não há motivos para a detenção, ainda menos para a convivência com pessoas já condenadas por crimes. Também falha o reconhecimento da necessidade de distinção de tratamento: mesmo quando os solicitantes não são detidos em prisões (nas quais eles necessariamente são introduzidos no sistema penal), são encaminhados para instalações análogas às prisionais, baseadas em padrões corretivos e nas quais o tratamento é aquele propagado pelo sistema penal - que entendemos ser baseada em punição (punir com a privação de liberdade aqueles que cometeram atos condenados pela sociedade), correção (corrigir um comportamento destoante daquele aceito pela sociedade na qual está inserido ou buscando inserir-se) e dissuasão (dissuadir outros indivíduos de tomarem as mesmas atitudes).

Os padrões do sistema penal acima mencionados são completamente inadequados para o trato da questão dos refugiados, pois são punidas com a privação de liberdade pessoas coagidas a abandonarem seu país de origem ou residência habitual. São indivíduos obrigados a deixar seus países de origem buscando proteção internacional e acreditando que ela se concretizará devido ao reconhecimento internacional de que o direito à vida, à liberdade e à segurança dos indivíduos deve ser respeitado e que, caso o país onde reside falhe em assegurá-lo, outro Estado, em conformidade com as disposições internacionais por ele acordadas, garanti-lo-á. Segundo Goodwin-Gill (2003), na maioria dos casos, somente se a demanda por refúgio for examinada antes que o indivíduo seja afetado pelo exercício da jurisdição estatal é que o Estado pode estar certo de que suas obrigações internacionais estão sendo cumpridas. Ademais, afirma esse autor, impor penalidade sem averiguar os méritos de uma demanda por refúgio provavelmente violará a obrigação do Estado de assegurar e proteger os direitos humanos de todos em seu território ou sujeitos à sua jurisdição - como estabelecido pelo PIDCP.

Igualmente, a Convenção de 1951 estabelece um regime de direitos (e responsabilidades) concernentes aos refugiados. Segundo seu art. 31:

1. Os Estados não aplicarão sanções penais aos refugiados que, chegando diretamente de ter- 
ritório no qual sua vida ou sua liberdade estava ameaçada, no sentido previsto pelo art. $1^{\circ}$, encontrem-se no seu território sem autorização, contanto que apresentem-se sem demora às autoridades e exponham-lhes razões aceitáveis para a sua entrada ou presença irregulares.

2. Os Estados Contratantes não aplicarão aos deslocamentos de tais refugiados outras restrições que não as necessárias; essas restrições serão aplicadas somente enquanto o estatuto desses refugiados no país de refúgio não houver sido regularizado ou eles não houverem obtido admissão em outro país. À vista desta última admissão, os Estados Contratantes concederão a esses refugiados um prazo razoável, assim como todas as facilidades necessárias(ONU, 1951).

Esse artigo aponta para a não privação de liberdade do solicitante a menos que necessário - e a necessidade não é simplesmente determinada pela sua entrada sem documentos apropriados no país, parâmetro utilizado nos Estados Unidos.

Embora os excertos citados do PIDCP e da Convenção de 1951 possam incitar interpretação que vise à proteção e observância dos direitos de refugiados e solicitantes de asilo, também apresentam brechas que possibilitam a manutenção da prática da detenção. Isso porque o PIDCP "permite" a detenção, desde que por "motivos previstos em lei e em conformidade com os procedimentos nela estabelecidos" e a Convenção menciona "restrições necessárias". É baseando-se em afirmações vagas como essas que alguns países concretizam políticas que destoam dos objetivos da Convenção, invocando o discurso da segurança nacional e restringindo sobremaneira a liberdade de solicitantes. Entretanto, no caso dos Estados Unidos, não há sequer uma justificativa para essas políticas que se fundamente em tais "brechas". As disposições na lei sobre a detenção de solicitantes de asilo não mencionam em momento algum os tratados internacionais com os quais esse Estado se comprometeu. Isso destaca a afirmação de Naumik (2008) de que no judiciário estadunidense existe uma difundida resistência em considerar o direito internacional no contexto da imigração. Essa autora sustenta ainda que tal constatação indica que, embora a arena seja legal, escolhas políticas estão entrando em jogo no que se refere à invocação do Executivo sobre a segurança nacional. Tudo isso evidencia uma situação em que a falta de coerção (enforcement) do regime internacional dos refugiados se traduz como característica que permite a desconsideração dos compromissos internacionais por meio da violação de direitos daqueles indivíduos que existem como sujeitos internacionais de direito, exatamente porque seus direitos haviam sido violados anteriormente em seu âmbito nacional - em um contexto, portanto, no qual o instituto do refúgio objetiva exterminar essa situação de violação.

Ainda que no caso dos regimes internacionais haja uma flexibilização da soberania estatal em prol de princípios, valores, normas e políticas acordados conjuntamente, a soberania representa um fator que não somente, em última instância, determina - o que é uma característica intrínseca em um sistema no qual o Estado-Nação ainda é o ator mais importante e dentro do qual tudo o que é acordado se realiza e cuja estrutura é necessária para a concretização -, mas que, nesse caso, funciona como entrave para que tais disposições venham a se materializar. É exatamente devido a essa configuração que se faz necessária a existência de uma estrutura de coerção para impedir que contra normas reconhecidas internacionalmente o Estado aja de acordo com interesses momentâneos ou propagandísticos. A não existência desse sistema de coerção faz com que, nesse caso especificamente, não simplesmente haja uma diminuição de lucros de grandes empresários (como é o caso das disposições de regimes como o de comércio internacional), mas que indivíduos fragilizados, vulneráveis devido à sua grave desconsideração como sujeitos de direito sejam inseridos em um contexto em que seus direitos continuam a ser violados. O que é completamente contra todo o histórico, assim como à justificativa filosófica e histórica para a existência do instituto do refúgio.

No que diz respeito ao regime internacional dos refugiados, além de não haver nenhum mecanismo de coerção, um aspecto central para ele, o processo de determinação do status de refugiado, é prerrogativa do Estado em que se solicita o refúgio. Embora tal determinação seja de natureza declaratória - o refugiado é a pessoa "que temendo ser perseguida [...]" (ONU, 1951) - a forma de fazê-la, por estar restrita ao âmbito estatal, é sujeita a diversas nuances, de modo que a concretização do regime pode estar em risco. Há indícios de que pessoas nos Estados Unidos podem erroneamente ter sido declaradas como não tendo "temor crível" de perseguição ou que foram desencorajadas de continuar sua candidatura ao refúgio (USCIRF, 2005a), além das mencionadas entrevistas por videoconferência - tanto para verificação do 
"temor crível" quanto para a determinação da elegibilidade - que alteram a percepção do juiz sobre o testemunho do solicitante (HUMAN RIGHTS FIRST, 2009).

Muitos dos problemas verificados nos Estados Unidos se relacionam ao fato de que o responsável pelas questões concernentes aos refugiados é o DHS, cuja missão é prevenir ataques terroristas nos Estados Unidos, reduzir a vulnerabilidade dos Estados Unidos ao terrorismo, minimizar seus danos e auxiliar na recuperação de ataques terroristas ocorridos no país (Homeland Security Act of 2002, Sec. 101(b)). Isso significa que a mesma estrutura responsável por assegurar que estrangeiros inadmissíveis e que possam realizar atos terroristas não entrem no país é aquela responsável - em uma etapa inicial - por assegurar que aos indivíduos fugindo de perseguição seja oferecida a oportunidade de conseguir proteção.

\subsection{Nos estados unidos, a mudança?}

Como afirmamos anteriormente, nos Estados Unidos há uma forte resistência à consideração do direito internacional no âmbito da imigração. Dessa forma, é rara a apresentação de justificativa quanto ao modo como a questão dos imigrantes é tratada: a política de restrição à entrada de imigrantes em seu território tornou-se senso comum sob a bandeira da segurança nacional. Todavia, devido à atenção e à contrariedade internacional que a prática da detenção de imigrantes fomenta, esse país tem tomado medidas no sentido de modificar seus procedimentos de contenção de imigração irregular. Nesse ambiente, os solicitantes de asilo recebem especial ênfase, posto que representam um conjunto de pessoas que demandam proteção internacional e têm, a seu favor, o caráter humanitário do refúgio.

Em tal contexto, o governo estadunidense divulgou em outubro de 2009 uma reforma do sistema de detenção imigratória. De fato, não houve a adoção de legislação a respeito, mas o anúncio de uma série de iniciativas do DHS visando aumentar a segurança e eficiência do sistema nacional de detenção, ao mesmo tempo em que se prioriza a saúde e a segurança dos detidos (ICE, 2009a). No que se refere aos solicitantes, particularmente, foi afirmado que seria iniciada a utilização de instalações específicas para esses grupos - as quais abrigassem populações não violentas e não criminosas. Ademais, o ICE indicou o provimento de pessoal para apoiar os procuradores na avaliação da credibilidade das reivindicações de asilo e na identificação e tratamento de fraudes (ICE, 2009a)

Em dezembro do mesmo ano, foi divulgado um documento pelo ICE a respeito dos novos procedimentos para a concessão da liberdade condicional de solicitantes. Foi reafirmado que são aptos a se beneficiarem da liberdade condicional os indivíduos que pudessem ter sua identidade estabelecida, que não representassem risco de fuga nem risco à comunidade e que não tivessem nenhum fator adicional contra sua liberação. A peculiaridade das novas diretivas reside no fato de que não é mais necessário que o solicitante requeira, por escrito, a liberdade às autoridades: o órgão responsável, tão breve quanto possível, após determinado o "temor crível", deve verificar a elegibilidade do indivíduo para a liberação.

Devido ao curto período desde o lançamento das iniciativas, ainda não é possível avaliar os efeitos do programa, principalmente devido à falta de divulgação dos dados relacionados aos imigrantes, em geral, e aos solicitantes de refúgio. Segundo o ICE, as conquistas referem-se a medidas para aumento da transparência relacionada à divulgação das mortes de pessoas detidas; o início da utilização de instalações específicas para pessoas que não cometeram atos de violência ou crimes; diminuição do número de instalações para a detenção; melhora das condições de detenção em alguns centros; desenvolvimento de propostas para implementação de medidas alternativas à detenção; lançamento de programas para determinar as necessidades medidas dos detidos; e lançamento de um sistema para localização dos detidos (ICE, 2012a). Por outro lado, algumas organizações começam a destacar a falta de efetividade das medidas tomadas rumo a uma alteração real da situação da detenção imigratória no país.

Em 2010, um relatório (NIJC; DWN; MCHR, 2010) elaborado por diversas organizações de direitos humanos traçou um panorama dos resultados das novas iniciativas. Segundo essa publicação, a implementação do programa para alternativas à detenção não foi bem sucedida. Dessa forma, o número total de detenções de imigrantes - inclusive de solicitantes de asilo - continua alto. Sobre a utilização de instalações específicas para pessoas que não cometeram crimes ou atos de violência, o relatório informa que houve, de fato, uma tentativa do ICE de manter os solicitantes em centros de detenção menos res- 
tritivos - o que é um avanço extremamente importante. No entanto, mesmo nesses centros, ainda há problemas como falta de privacidade para a interação dos detidos com seus representantes e acesso limitado à recreação.

Esse relatório assevera ainda um progresso importante em relação à questão: há relatos sobre aumento do número de solicitantes que se beneficiaram da liberdade condicional após a revisão das medidas do ICE relacionadas a esse procedimento (NIJC; DWN; MCHR, 2010). Isso significa que a principal alteração das disposições que concernem aos refugiados pode ter demonstrado efeitos positivos no sentido de melhorar as condições de recepção a esse grupo de pessoas. Contudo, ainda não é possível mensurar a extensão exata desses efeitos de modo a avaliar a eficiência da medida.

O relatório elaborado pela Human Rights First, em 2011, por outro lado, assevera que a vasta maioria dos detidos - imigrantes e solicitantes de asilo - continua sendo mantida em prisões ou instalações a elas análogas, com todos os prejuízos desse tipo de sistema: utilização de uniformes, encarceramento em ambientes fechados durante a maior parte do dia, contato com amigos e familiares através de vidro e pouca privacidade (HUMAN RIGHTS FIRST, 2011). Outra questão preocupante refere-se ao fato de que o DHS e o Departamento de Justiça, em 2010, recusaram-se a tomar medidas para prover acesso às audiências perante cortes de imigração de solicitantes detidos após requererem proteção nos aeroportos e fronteiras estadunidenses ${ }^{16}$ (HUMAN RIGHTS FIRST, 2011). Ademais, a maior parte dos detidos - solicitantes e imigrantes - não é representada durante o processo de remoção e sequer recebe informações básicas sobre a lei de imigração.

A despeito das críticas, a Human Rights First identifica aspectos positivos derivados da mencionada reforma: diminuição da quantidade de centros de detenção,

\footnotetext{
${ }^{16}$ Em março de 2010, diversas organizações não governamentais submeteram ao Departamento de Justiça dos Estados Unidos uma petição na qual requereram a adoção de regras garantindo a juízes de imigração a autoridade de revisar a custódia de estrangeiros que cheguem às fronteiras do país buscando asilo. Essa petição, assinada por 31 organizações, não logrou seu objetivo, tendo sido suas recomendações rejeitadas (HUMAN RIGHTS FIRST, 2011). A petição pode ser acessada em: <https:/www.immigrantjustice.org/sites/ immigrantjustice.org/files/NIJC\%20Petition\%20for\%20Rulemaking\%20doj\%20\%20final2\%202010\%2003\%2015.pdf>.
}

implementação do localizador virtual de detidos, alteração da política de liberdade condicional para solicitantes, treinamento e alocação de monitores em algumas instalações para relatar a implementação das medidas e publicação de novos direcionamentos sobre a discricionariedade processual - que podem impactar as decisões sobre liberação dos detidos (HUMAN RIGHTS FIRST, 2011). No entanto, ressalta-se que os avanços observados ainda são poucos, e aponta-se a grande necessidade de implementação das diretrizes estabelecidas pela nova política para que os Estados Unidos ajam de acordo com seus comprometimentos internacionais relacionados a direitos humanos.

Novamente é interessante notar que os princípios a serem considerados e os objetivos a serem buscados no que se refere à temática do refúgio destoam fortemente daqueles dos órgãos encarregados nos Estados Unidos de tratar o tema. Quando nos referimos a refugiados, aludimos a um instituto criado no âmbito internacional que remete a direitos humanos, responsabilidade internacional compartilhada e caráter humanitário. No Estado em questão, o asilo é responsabilidade estrita de um órgão que, como mencionamos, tem como característica central de atuação a luta contra o terrorismo. Tal discordância evidencia-se claramente nas manifestações do ICE. Em uma nota publicada no site do DHS, o ICE explicitou a reforma do sistema de detenção imigratória e, na curta seção que dedicou à questão dos solicitantes, ressaltou o benefício da nova política de liberdade condicional, qual seja, a redução dos gastos do governo (ICE, 2012b). A partir do próprio documento que estabelece as diretrizes sobre essa política, é possível a constatação da preocupação do departamento com as possíveis consequências dos novos parâmetros:

This directive is an internal policy statement of ICE. It is not intended to, shall not be construed to, may not be relied upon to, and does not create, any rights, privileges, or benefits, substantive or procedural, enforceable by any party against the United States, its departments, agencies, or other entities, its officers or employees, or any other person (ICE, 2009b).

É evidente, portanto, que as alterações demonstram a percepção dos benefícios econômicos que podem decorrer das novas práticas, em detrimento do entendimento de que as políticas até então aplicadas não condiziam com o tratamento que o instituto do refúgio compreende como pertinente aos solicitantes de asilo. De 
modo que, se atualmente os parâmetros são - ao menos em teoria - mais benéficos aos solicitantes, podem se tornar, de modo rápido, mais restritivos - conforme as necessidades percebidas pelo Estado.

Os solicitantes de refúgio vêm sendo, assim, inseridos no contexto de securitização da imigração, um processo político e intelectual de identificação da imigração como ameaça e sua inserção no domínio e na agenda da segurança (REIS; BRACANTE, 2009). Essa securitização da imigração tem se manifestado em duas esferas, a de defesa - que engloba preocupações concernentes ao terrorismo e à criminalização dos estrangeiros -, assim como a econômica e social - que têm ressaltado questões relacionadas a postos de trabalho e manifestações xenófobas, que questionam a legitimidade da presença do estrangeiro. Por esse motivo, a nossa afirmação de que a detenção desses indivíduos não somente contribui para a ideia de que eles estão sendo criminalizados, mas é sim baseada em uma visão criminalizada e criminalizante, já que deriva da ideia do imigrante e do solicitante de refúgio como possíveis criminosos e, ao mesmo tempo, estimula a propagação dessa visão por meio de sua inserção no sistema penal ou análogo ao prisional.

Em um contexto de falta de coerção e de má alocação departamental das questões relacionadas ao refúgio, os solicitantes de asilo nos Estados Unidos têm sido introduzidos nessa conjuntura perversa e vêm sofrendo as consequências dessa inserção, sem que se considere que o seu processo migratório é forçado e se fundamenta em considerações que, muitas vezes, são de simples proteção da vida. O instituto do refúgio foi formulado objetivando a proteção da pessoa, ou seja, a retirada do indivíduo de um contexto de violação à sua vida, liberdade ou segurança. Entretanto, para que tal proteção seja concretizada, alguns seres humanos têm sido submetidos a medidas que violam esses mesmos direitos. Nesse cenário, migrar por ser coagido não é um crime - é um direito -, mas ser detido por migrar é uma punição. Punição nesse contexto de migração forçada é violação, e essa violação é o que deve ser detido.

\section{Referências}

ALEXANDER, Barbara Cochrane. Detention of asylumseekers in the United States. Human Rights Brief, v. 7, n. 2, Washington, 2000. Disponível em: <http:// digitalcommons.wcl.american.edu/hrbrief/vol7/iss $2 />$. Acesso em: 16 maio 2012.

AMNESTY INTERNATIONAL. Rights on the move: refugee, asylum-seekers, internally displaced people and migrants. London, 2007. Disponível em: <http:// www.amnesty.org/en/library/asset/pol33/001/2007/ en/d2dd4528-d3c4-11dd-8743-d305bea2b2c7/ pol330012007en.pdf $>$. Acesso em: 20 maio. 2012.

ANDRADE, José H. Fischel de. Direito internacional dos refugiados: evolução histórica (1921 -1952). Rio de Janeiro: Renovar, 1996.

BARRETO, Luiz Paulo T. F. Das diferenças entre os institutos jurídicos do asilo e do refúgio. Brasília: IMDH, 2006. Disponível em: <http://www.migrante.org.br/ textoseartigos.htm>. Acesso em: 20 maio 2012.

CANÇADO, Antônio Augusto Trindade. Tratado de direito internacional dos direitos humanos. Porto Alegre: Sergio Antonio Fabris Editor, 1999. v. 1.

CRISP, J. Africa's refugees: patterns problems and policy challenges. (New Issues in Refugee Research, Working Paper n. 28). Geneva: ACNUR, 2000. Disponível em: $<$ http://www.unhcr.org/3ae6a0c78.html>. Acesso em: 20 maio 2012.

EDWARDS, Alice. Back to basics: the right to liberty and security of person and 'alternative detention' of refugees, asylum seekers, stateless persons and other migrants. Geneva: UNHCR, 2011. Disponível em: <http://www. unhcr.org/refworld/docid/4dc935fd2.html>. Acesso em: 20 maio 2012.

FELLER, Erika. Address to the conference of the international association of refugee law judges at Bern, Switzerland. Georgetown Immigration Law Journal, Washington, v. 15. p. 381-389, 2000-2001. Disponível em: $<$ http://www.unhcr.org/refworld/docid/42b96fa92.html >. Acesso em: 20 maio 2012.

FIELD, Ophelia; EDWARDS, Alice. Alternatives to the detention of asylum seekers and refugees. Geneva: UNHCR, 2006. Disponível em: <http://www.unhcr.org/ cgi-bin/texis/vtx/refworld/rwmain?docid=4472e8b84\&p age $=$ search $>$. Acesso em: 20 maio 2012.

FOSTER, Michelle. International refugee law and socioeconomic rights: refugee from deprivation. New York: Cambridge University Press, 2007. 
GORLICK, Brian. Refugee protection in troubled times: reflections on institutional and legal developments at the crossroads. In: STEEINER, Niklaus; GIBNEY, Mark; LOESCHER, Gil (Ed.). Problems of protection: the UNHCR, refugees and human rights. Routledge: New York, 2003. p. 79 - 99.

GOODWIN-GILL. Article 31 of the 1951 Convention Relating to the Status of Refugees: non-penalization, detention, and protection. In: FELLER, Erika; TURK, Volker; NICHOLSON, Frances (Ed.). Refugee protection in international law: UNHCR's Global Consultations on International Protection. Cambridge: Cambridge University Press, 2003. p. 185-252. Disponível em: <http://www.unhcr.org/refworld/docid/470a33b10. html>. Acesso em: 20 maio. 2012.

HUMAN RIGHTS FIRST. U. S. Detention of asylum seekers: seeking protection, finding prison. New York, 2009. Disponível em: <http://www.humanrightsfirst. org/wp-content/uploads/pdf/090429-RP-hrf-asylumdetention-report.pdf $>$. Acesso em: 20 maio 2012.

HUMAN RIGHTS FIRST. Jails and jumpsuits: transforming the US immigration detention system - a two-year review. New York, 2011. Disponível em: <http:// www.humanrightsfirst.org/wp-content/uploads/pdf/ HRF-Jails-and-Jumpsuits-report.pdf $>$. Acesso em: 20 maio 2012.

IBHAWOH, Bonny. Defining persecution and protection: the cultural relativism debate and the rights of refugees. In: STEEINER, Niklaus; GIBNEY, Mark; LOESCHER, Gil (Ed.). Problems of protection: the UNHCR, refugees and human rights. Routledge: New York, 2003. p. $61-75$.

IMMIGRATION AND CUSTOMS ENFORCEMENT. Detained asylum seekers fiscal year 2007. 2008. Disponível em: <http://www.ice.gov/doclib/foia/hrifa/ fy07hrifasection903report.pdf $>$. Acesso em: 20 maio 2012.

IMMIGRATION AND CUSTOMS ENFORCEMENT. ICE detention reform: principles and next steps. 2009a. Disponível em: <http://www.dhs.gov/xlibrary/assets/ press_ice_detention_reform_fact_sheet.pdf $>$. Acesso em: 20 maio 2012.

IMMIGRATION AND CUSTOMS ENFORCEMENT. Parole of arriving aliens found to have a credible fear of persecution or torture. 2009b. Disponível em: <http:// www.ice.gov/doclib/dro/pdf/11002.1-hd-parole_of_ arriving_aliens_found_credible_fear.pdf $>$. Acesso em: 20 maio 2012.
IMMIGRATION AND CUSTOMS ENFORCEMENT. Detention reform accomplishments. 2012a. Disponível em: <http://www.ice.gov/detention-reform/detentionreform.htm>. Acesso em: 20 maio 2012

\section{IMMIGRATION AND CUSTOMS ENFORCEMENT} Written testimony of U.S. immigration and customs enforcement office of detention policy and planning assistant director Kevin Landy for a house committee on the judiciary, Subcommittee on Immigration Policy and Enforcement Hearing on Performance-Based National Detention Standards (PBNDS). 28 maio 2012. Disponível em: <http://www.dhs.gov/ynews/testimony/20120328ice-detention-standards-hjc.shtm>. Acesso em: 20 maio 2012.

JUBILUT, Liliana Lyra. O Direito internacional dos refugiados e sua aplicação no ordenamento jurídico brasileiro. São Paulo: Método, 2007.

LOESCHER, Gil. Human rights and forced migration. In: GOODHART, Michael. Human rights: politics and practice. New York: Oxford University Press, 2009. p. 239-259.

McNAMARA, Dennis. Opening Address. In: MCNAMARA, Dennis; GOODWIN-GILL, Guy. UNHCR and international refugee protection. Oxford, p. 14-20, June 1999. Disponível em: <http://repository.forcedmigration. org/show_metadata.jsp?pid=fmo:4350>. Acesso em: 20 maio 2012.

NAUMIK, Alicia Triche. International Law and detention of US asylum seekers: contrasting matter of D-J- with the United Nations Refugee Convention. International Journal of Refugee Law, Oxford, v. 19, n. 4, p. 661-702, feb. 2008. Disponível em: <http://ijrl.oxfordjournals.org/ content/19/4/661.short $>$. Acesso em: 20 maio 2012.

NATIONAL IMIGRANT JUSTICE CENTER. Human rights and the Obama administration's immigration detention reform. 2010. Disponível em: $<$ http://www. immigrantjustice.org/sites/immigrantjustice.org/files/ ice $\% 20$ report $\% 20$ card $\% 20$ full $\% 20$ final $\% 202010 \% 20$ 10\%2006.pdf>. Acesso em: 20 maio 2012.

OLIVEIRA, Adriana Capuano de. Direito à mobilidade individual e à soberania dos Estados. Estudos Avançados. São Paulo, v. 21, n. 61, p. 323- 327, set./dez. 2007.

ONU. Convenção relativa ao Estatuto dos Refugiados. 1951. Disponível em: <http://www.direitoshumanos. usp.br/index.php/Refugiados-Asilos-Nacionalidades-eAp\%C3\%A1tridas/convencao-de-genebra-relativa-aoestatuto-dos-refugiados.html>. Acesso em: 20 maio 2012. 
ONU. Declaração Universal dos Direitos Humanos. 1948. Disponível em: <http://portal.mj.gov.br/sedh/ct/legis_ intern/ddh_bib_inter_universal.htm $>$. Acesso em: 20 maio 2012.

ONU. Pacto Internacional dos Direitos Civis e Políticos. 1966. Disponível em: <http://www. direitoshumanos.usp.br/index.php/Sistema-Global.Declara\%C3\%A7\%C3\%B5es-e-Tratados-Internacionaisde-Prote $\%$ C3\%A7\%C3\%A3o/pacto-internacional-dosdireitos-civis-e-politicos.html>. Acesso em: 20 maio 2012 .

PHYSICIANS FOR HUMAN RIGHTS AND THE BELLEVUE/NYU PROGRAM FOR SURVIVORS OF TORTURE. From persecution to prison: the health consequences of detention for asylum seekers. Boston, New York, 2003. Disponível em: <https://s3.amazonaws. com/PHR_Reports/persecution-to-prison-US-2003. pdf>. Acesso em: 20 maio 2012.

REIS, Rossana Rocha; BRANCANTE; Pedro Henrique. A "Securitização da imigração": mapa do debate. Lua Nova, São Paulo, v. 77, p. 73-104. 2009. Disponível em: <http:// www.scielo.br/pdf/ln/n77/a03n77.pdf $>$. Acesso em: 20 maio 2012.

UNHCR. Detention of asylum-seekers and refugees: the framework, the problem and recommended practice. Geneva, 4 jun. 1999. Disponível em: <http://www.unhcr. org/refworld/pdfid/47fdfaf33b5.pdf> Acesso em: 20 maio 2012.

UNHCR. Note on accession to international instruments and the detention of refugees and asylum seekers. 1986. Disponível em: <http://www.unhcr.org/refworld/ docid/3ae68cce18.html>. Acesso em: 20 maio 2012.
UNITED STATES OF AMERICA. Homeland Security Act, 2002, de 25 de novembro de 2002. Disponível em: <http://www.dhs.gov/xabout/laws/law_regulation_ rule_0011.shtm>. Acesso em: 20 maio 2012.

UNITED STATES OF AMERICA. Immigration and Nationality Act, de 24 de dezembro de 1952. Disponível em: <http://www.uscis.gov/portal/site/uscis/menuitem. f6da51a2342135be7e9d7a10e0dc91a0/?vgnextoid=fa7e5 39dc4bed010vgnvcm1000000ecd190arcrd\&vgnextchann el=fa7e539dc4bed010vgnvem 1000000ecd190arcrd\&ch= act>. Acesso em: 20 maio 2012.

UNITED STATES OF AMERICA. Title 8 of Code of Federal Regulations (8 CRF). Disponível em: <http://www.uscis.gov/portal/site/uscis/menuitem.Eb1d4c2a3e5b9ac89243 c6a7543f6d1a/?Vgnextoid=64929c7755cb9010vgnv $\mathrm{cm} 10000045 \mathrm{f} 3 \mathrm{~d} 6 \mathrm{a} 1 \mathrm{rcrd} \& \mathrm{Vgnextchannel}=64929 \mathrm{c} 7755 \mathrm{cb}$ 9010 vgnvem $10000045 f 3 d 6 a 1$ rcrd $>$. Acesso em: 20 maio 2012.

USCIRF. Report on asylum seekers in expedited removal. v. 1. Washington, 2005a. Disponível em: <http://www.uscirf.gov/images/stories/pdf/asylum_seekers/Volume_I. pdf>. Acesso em: 20 maio 2012.

USCIRF. Report on asylum seekers in expedited removal. Washington, 2005b. v. 2. Disponível em: <http://www. uscirf.gov/images/stories/pdf/asylum_seekers/ERS_RptVolII.pdf>. Acesso em: 20 maio 2012.

WELCH Michael; SCHUSTER, Liza. Detention of asylum seekers in the US, UK, France, Germany and Italy: a critical view of the globalizing culture of control. Criminal Justice, v. 5, p. 331-355, 2005. Disponível em: <http:// crj.sagepub.com/content/5/4/331.full.pdf + html $>$. Acesso em: 20 maio 2012 . 